\title{
Influence and Importance of Cinema on the Lifestyle of Educated Youth: A study on University Students of Bangladesh
}

\author{
Istiak Mahmood \\ Sociology Discipline, Khulna University, Bangladesh
}

\begin{abstract}
Cinema is the most complex and powerful art form in the present world. It can help us to better understand our own lives, the lives of those around us and even how our society and culture operate. They can shed light on political and spiritual matters too and can provide catharsis and perspective and may open our eyes to new ways of thinking, feeling and pursuing our lives. Bangladesh has got a rich tradition of cinema, though present condition is not so appreciable. University students are the most important part for the future of Bangladesh. In all the important stages of our history students played a vital role. Even in the emergence of Bangladesh students had the most aggressive involvement .Our students were always aware about the society, it's people, our culture. In the present world of globalization everything is getting available, easier and close in contact. Cultural exchange were never fast before as it is right now. Technology, cultural phenomena, ethical views are changing not in every day, but in every second now. In this context $i$ started my research on the relation of film and university students of Bangladesh. For different causes students don't go to cinema halls to watch Bengali movie, they watch it in computer now and for the technology like television and internet they are coming on the close contact of foreign(like Indian and western) ethics, rituals and culture, which certainly has some impact on them. Conducting research on several public and private universities it's clear that this influence has both negative as well as positive side. Students are conscious about their cultural diffusion and interchange. By analysing the trend, attitude, lifestyle and outlook about life of the university students it could
\end{abstract}

be said that there is a certain influence of films on university students of Bangladesh.

Keywords: Cinema, Globalization, Lifestyle, Communication, Culture.

\section{Introduction, Rationale and statement of the concept}

Cinema has been one of the greatest influences in our modern life, and it's also a form of art, the seventh art along with photography, architecture, literature, play, painting and music. It's the combination of technology, business, entertainment and aesthetics, each and everything of these four has important role in present day world and it's also visible in the variation of its forms, Film is technology(picture taken in the celluloid camera and editing),movie is the business and entertainment, and cinema is the aesthetics.

Cinema, popular or parallel, a visual art of story-telling with rich inputs of music, screenplay, cast and script, mirrors the contemporary society in which it functions. From emotional dramas to candyfloss romances to action-thrillers, cinema derives its sustenance, ideas and imaginations from its surroundings. The images cinema creates, surreal or tangled wave of deceit, need to be in sync with societal aspirations and basic urge of humanity to recreate and have fun and entertainment. In its long journey of more than a century, cinema has transformed itself from being a taboo and absolute no-no to a virtual way of life. Social dynamics have always regulated the content of cinema. The main protagonist of any film fights villains who are manifestations of contemporary societal evils - from village money-lender to land-hawks to advocates of dowry, dons and modern day terrorists. It provides a platform that reflects the growth of economy, politics, technological advancements. Films are useful for knowing the history of ancient world. A lot of countries of the world are involved with Film making through their own industry, among them the most powerful, organized, popular and influential is Hollywood which entertains the total world population and not only that it surprises the world with the advancement of technology. A movie is not only a visual treat to its audience but it also an account of societal, economic and political set up in which a person is living. If we want to acquire the critical tools to understand the medium of film in the context of economic, industrial, social and cultural factors, from its beginnings in 1895 right up to the present day, then we must have to work on this .In Bangladeshi point of view, university students are the most potential resource of our country. In the world map we're one of the poor but promising country and a lot of hope are reserved on manpower and universities are the key place to produce quality human being. For the globalization around the world media and art has opened throughout the earth. Now it's possible to get an American movie today in Bangladesh which has released there yesterday. By this availability trends about thinking and total lifestyle has changed a lot. Generally it could be called as westernization but there is 
something more on that. Without knowing the student's thinking condition and level towards life and society, we can't fix our expectations from them. and this study is significant in present circumstance because it aims to find out different aspects of human behaviour which is a big deal of all time, without any suspicion.

\section{Methodology}

The study has been conducted through the use of survey design. Data has been collected from the university students. To realize the wide objectives of the study, data about respective concepts has been collected through incorporating relevant items (variables) in the questionnaire and analysed and interpreted using descriptive techniques. Purposive sampling was used to collect data from the field. Total sample size was 120. A questionnaire was developed and finalized through pre-test and used for data collection. Data has been computerized, analysed and interpreted by using softwares like SPSS, Excel and findings were presented through Microsoft word! The selected universities are:- (public)Khulna university, Khulna, Dhaka university, Dhaka, Rajshahi university, Rajshahi, Mawlana Vasani science and technology university, Tangail, Patuakhali science and technology university, Patuakhali.

(Private) Brac university, Dhaka, North-south university, Dhaka, East-west university, Dhaka, American international university, Dhaka, Independent university, Dhaka, Asian university, Khulna, Northern university, Khulna.

\section{Literature Review}

There have been quite a few studies about the media impact on society as a whole in the different parts of the world. Some researches have also been done about the impact of it on specific group of people. But talking about Bangladeshi contribution, we almost haven't found any work on that save the only relevant work done by Nurul Alam Atique in his 'Notun cinema, somoyer proyojone'(2009). This book is a collection of newspaper column where writer wants to elaborate the necessity and role of youth to create a new horizon of cinema in Bangladesh and elaborates what type of movies Bangladeshi youth wants to see and their different views about the contemporary situation of this sector.

But the above study does not explicitly include the direct contact with university students of Bangladesh and search the hidden factors of it.

\section{Analysis and the vice versa impact}

From the TABLE below we can see that, among the respondents $34.16 \%$ passes their leisure time by watching movies. $26.66 \%$ by reading books , $16.66 \%$ by listening songs and $22.5 \%$ by other activities like gardening, pets, social work, sleeping etc. which clearly suggests that there is a close connection between their lives and what they're watching in the screen. Those who don't generally pass their leisure time by watching movies doesn't mean that they don't watch movies at all, it's just not their most favourite pastime but they love watching sometimes.

Table 1: Movie as a pastime

\begin{tabular}{lll}
\hline Passing of leisure time & Number of respondents & $\%$ \\
\hline Books & 32 & $26.66 \%$ \\
Movies & 41 & $34.16 \%$ \\
Songs & 20 & $16.66 \%$ \\
\hline Other & 27 & $22.5 \%$ \\
\hline
\end{tabular}

They were talking about the influence of Hindi movies in weddings and other closely related functions of our life. From the TABLE below we can see that, $90 \%$ of the respondents think that changing our rituals, behaviour, outlook towards life is somehow connected with what we see on screen. They also thinks that increasing of violence, sexual assault, illegal ways of quick money making and other social problems has a direct connection with movies. Almost all of them agrees that movies has an important role in trendsetting.

Table 2: Response about the impact

\begin{tabular}{lll}
\hline Change in rituals, outlook, attitude through movies & Number of respondents & $\%$ \\
\hline Yes & 108 & $90 \%$ \\
No & 12 & $10 \%$ \\
\hline
\end{tabular}

Why we love or watch movies that couldn't be a single statement. A lot of arguments are there as well as lot of controversies. Movies affect many of us powerfully because the combined impact of images, music, dialogue, lighting, sound and special effects can elicit deep feelings and help us reflect on our lives. They can help us to better understand our own lives, the lives of those around us and even how our society and culture operate. They can shed light on political and spiritual matters too and can provide catharsis and perspective and may open our 
eyes to new ways of thinking, feeling and pursuing our lives. There are many ways to harness the power of movies to heal, grow and change. Bangladeshi university students got lots of variety in economic, social and cultural sense like other countries. so, we can't measure our students as a whole or as a representative of an institution. Private university is a comparatively new concept in Bangladesh, in general sense it assumes that the economic condition of the students of these universities are well than the public university students. The faith that many social scientists have in film as providing them with an 'objective recording instrument' is touching and almost sentimental.

Like most forms of art and media, film reflects the eternal human search for truth, a process where we can discuss it as both cause and effect. Bangladeshi university students are very conscious about the existing social life but there is a communication gap between the students and the mass people. We can discuss this in the context of globalization and capitalism. In capitalism capitalists earn money whatever the way, ethics takes very small part here. The picturisation of this type of lifestyle makes university students aware about their career but not to care about others, "individualism" is the major concept here. Most of the students watch movie in computer. They don't take the opportunity to feel the "larger than life experience". They deliberately dislike the environment of the cinema halls which, in their terms is 'uncultured people's place! A lot of students who wants to know the techniques and technologies behind a movie making process which is making them interested to know the ultramodern and up to date technologies.

Besides, movies have a lot of influence on our outlook about everyday life and it has an important impact on observation ability. A good audience could see many things which is hidden to the other ordinary people. Youth is the time when people wants to through away the polluted environment of the society and youth is the best time to work for it. we have watched our youths specially university students took part in every major incidence of our national life. From the language movement to mass movement of 69, everywhere and in 1971, liberation war could not be won by us if students did not take part on it. After the liberation we saw decrease in every sector, in the ethics level of the students too. But, when time came in 90's students again played their role properly. This active youth know how to lead, how to live. A lot of efforts of making movie was inspired by them also. They were inspired by a lot of movies or movie making efforts. Bangladesh is a country where we live in capitalism, in the costume of feudalism. Here economic stratification is immense and for economy every section of society is stratified. We know, Economy is the basic structure and everything else including education, religion, society is super structure. Movie taste is also influenced by this factor. Those who live in the environment of well-equipped everything, get whatever they need, their connection with the outer world is a lot more than the students don't have enough money to buy newly arrived DVDs. Bangladeshi universities are still not capable enough to produce information accessibility to all it's students. so ,students has to arrange it from themselves and here comes the question of money. From the answer of the respondents we came to know that most of the public university students thinks that private university students get more opportunities to know and accumulate movies than them .so, they are connected with the up to date news but when comes the question of movie taste they don't think any better position from them. On the other hand private university students don't have any proper idea about the movie taste of the public university students. Bangladeshi university students wants to put Bangladeshi movie in the global map. They wants to take part on it, whatever their role, as a maker, technician or as a conscious viewer.

\section{Conclusion}

Bangladesh has a long tradition of quality movies from the very first "Mukh O Mukhosh" to the very recent one. Certainly movie is the reflection of society which works to change the existing condition of it. It's probably just a coincidence, though an appropriate and striking one, that movies came into existence just as America was experiencing a major shift into the very values that would allow movies to thrive and flourish. At the end of the 19th century, nothing was more admired in an individual than character. Traits like discipline, sobriety and reliability were especially prized, traits that most suited a person for success in the late 19th century economy. In those days men worked for themselves, as farmers and small businessmen, and made their way through single-minded diligence. This changed in the first decades of the 20th century. The majority of people began working in metropolises, for corporations, instead of starting their own businesses. In this new environment, character was secondary. Personality was of primary importance -- being affable, engaging, innovative, and good-looking. The ideal individual of 1900 was a stuffed shirt in the eyes of 1925 (just as the ideal man of 1925 would have been considered a lightweight by the standards of 1900). In the dawning modern age, a premium was placed on sex appeal, since men and women were suddenly working together again, for the first time since the industrial revolution. Thus, American culture began its love affair with surfaces, at the precise moment when a new art form was coming in that did nothing but record surfaces, an art form dedicated to making surfaces as alluring as the human mind could devise. Is there any wonder why movies grew to become a sensation? In an age that rewarded and celebrated personality, movies mythologized, glorified and enshrined personalities. Cinemas have persistently dealt with the problems of the society, and brought out the 
darkest secrets of the world as it is today. The thought that a movie always equals entertainment is but a myth. I would like to salute the filmmakers, actors, and producers who have done and are still doing their bit to let the people know about the society better. So, as a conclusion I would like to restate and make clear that cinemas are undeniably reflective of the society that we live in, the strong link between "reel" and "real" is here to stay and cinema influenced our lifestyle vice versa as well.

\section{Reference}

[1] Kabir,Alamgir;The cinema of Pakistan,Shandhani,Dhaka,1969

[2] Haque,Fahmidul\&Nasrin, GeetiAra;Bangladeshercholochitroshilpo:sonkote jonosonoskriti,Srabon,Dhaka,2008

[3] Kabir,Alamgir;Films in Bangladesh,Bangla academy,Dhaka,1979

[4] Roy, Satyajit;Bisoy:Cholochitro,Ananda,Kolkata,1976

[5] Giddens, Anthony;Sociology,polity,london,2000

[6] Atique,NurulAlam;Notuncinema:somoyerproyojon,Pandulipi karkhana,Dhaka,2009

[7] Young,Pauline V. ,Scientific social surveys and research,Printicehall,New jersey,1956

[8] Berger, Arthur(edi.);Film in society,New york,1980 Hawkins,Gordon\&Gimring, Franklin E.;Pornography in a free society,Cambridge university press, 1991

[9] Mehernosh,Kapadia;Society,London,2003 